\title{
RESIDÊNCIA PEDAGÓGICA: um olhar sobre a escola a partir da educação do campo no Estado do Paraná
}

\section{Ana Cristina Hammel ${ }^{1}$ \\ FERNANDA MARCON ${ }^{2}$}

\section{Introdução}

O texto que ora sistematizamos é resultado do trabalho do núcleo de Educação do Campo do Programa Residência Pedagógica desenvolvido na Universidade Federal da Fronteira Sul (UFFS), campus Laranjeiras do Sul, PR. A Educação do Campo abrange três núcleos compostos por acadêmicos/as de Laranjeiras do Sul e Erechim. Nesses três núcleos são atendidos aproximadamente 70 acadêmicos/ as e 12 escolas do campo. No núcleo sob nossa responsabilidade, atuam 20 acadêmicos/as de diferentes regiões do estado do Paraná, com diferentes características e especificidades que serão debatidas no decorrer do trabalho.

O Programa é uma ação governamental desenvolvida pela Coordenação de Aperfeiçoamento de Pessoal de Nível Superior

\footnotetext{
1 Doutoranda em História na Unioeste, Campus Marechal Cândido Rondon. Mestre em Educação pela UNIOESTE. Docente da Universidade Federal da Fronteira Sul, Campus Laranjeiras do Sul Contato: ana.hammel@uffs.edu.br.

2 Doutora em Antropologia Social, professora-adjunta da UFFS, coordenadora de núcleo do Programa Residência Pedagógica em Educação do Campo, campus Laranjeiras do Sul. Contato: fernanda.marcon@uffs.edu.br.
} 
(CAPES) desde 2018. A partir da adesão institucional, a UFFS passa a organizar subprojetos nos diferentes colegiados dos cursos e campi nos três estados da sua abrangência. Em Laranjeiras do Sul, os Cursos de Licenciaturas Interdisciplinares em Educação do Campo apresentam um subprojeto na área de Educação do Campo.

A partir da formulação de um subprojeto, e considerando a diversidade dos cursos de Educação do Campo na UFFS, foram formados os núcleos para atuação em diferentes escolas, que são também os campos de estágios dos acadêmicos desses cursos. A vinculação com o estágio, que a princípio foi entendida como uma oportunidade de qualificação do Programa e dos próprios estágios, apresentou uma série de limites, os quais não poderiam ser esgotados neste artigo, mas que trazemos como reflexão inicial de nossas práticas no Programa Residência Pedagógica.

Neste texto, portanto, elencamos alguns elementos observados durante seis meses de ação do Programa nas escolas caracterizadas na sequência. Esses elementos são centrais para se pensar a qualidade da execução do subprojeto em andamento e os objetivos já descritos. Assim, priorizamos adentrar nos elementos centrais que constituem a singularidade, a especificidade e a particularidade da Educação do Campo e dos cursos de formação inicial de professores para o campo, sendo a alternância pedagógica a articuladora de reflexões mais amplas sobre a escola e o processo de residência pedagógica.

\section{As Condições da Residência Pedagógica em Cursos de Alternância}

Como docentes em um curso de Educação do Campo em regime de alternância, entendemos que o processo e a orientação de pensar a educação - e a escola - "em movimento" é ainda mais

3 Sobre a "pedagogia do movimento", ver Caldart et al. (2012). 
urgente. As/os estudantes do curso vêm de diferentes comunidades dos estados do Paraná e de Santa Catarina e circulam por universos culturais e socioeconômicos muito distintos. Os desafios em sua formação se apresentam a cada etapa do tempo universidade, requerendo das/dos docentes um olhar sensível e atento às especificidades de estudantes indígenas, camponeses/as, acampados/as, assentados/as e agricultores/as familiares. As/os estudantes que participam do PRP trazem para a experiência da residência pedagógica todos esses desafios e uma vivência muito próxima daquela vivida pelos estudantes com os quais se relacionam nas escolas do campo. Isto é, as mesmas dificuldades de se manterem estudando e participando ativamente da vida da escola/universidade atravessam o processo de residência e as vivências de estudantes das escolas do campo. A especificidade da educação do campo nos direciona a pensar a escola a partir de seu diálogo permanente com a vida, com a realidade que a constitui. A escola como produtora de uma leitura aprofundada e crítica da realidade, aliada às lutas e aos anseios da comunidade transformadora e emancipadora.

Nesse sentido, os núcleos do PRP na UFFS Laranjeiras do Sul foram constituídos pensando nas especificidades dos/as estudantes do curso, procurando contornar as inúmeras dificuldades para desenvolver as atividades do subprojeto, estreitar os laços com as escolas e suas comunidades e seguir com as atividades do curso de graduação. O tempo comunidade representa um afastamento físico da universidade, que pode ser ainda mais simbólico se não há de nossa parte, como coordenadoras do PRP e por parte dos/das estudantes residentes, a preocupação em manter a conexão necessária entre os diferentes espaços que constituem nossas práticas e reflexões (a universidade, as escolas e suas comunidades, as comunidades e as vivências dos/as estudantes). É essa conexão que nos faz tomar os inventários da realidade produzidos pelo Programa como 
resultado de um complexo lugar de observação, isto é, uma observação e uma reflexão também em movimento. Esse processo todo se dá a partir da compreensão da Educação do Campo como lócus específico de forma de ser escola e que exige um professor/educador que dialogue com a especificidade. Assim, consideramos fundamental a compreensão desse processo a partir da construção feita no Estado do Paraná.

\section{A Especificidade da Educação do Campo no Estado Paraná}

O processo de constituição da Educação do Campo no Paraná tem data recente e remete ao processo de luta e de organização dos trabalhadores do campo por escola e políticas de formação para os educadores do campo. Embora seja uma característica do estado, as pequenas comunidades e a diversidade de produção e organização dos/as trabalhadores/as do campo, a educação sempre ocupou um lugar marginal, com pouco investimento público, mas com grande significado dentro das comunidades. A escola sempre foi um espaço aglutinador, espaço de convivência, de encontros e de debates sobre questões importantes. O/a professor/a, mesmo aqueles/as com pouca formação se tornam referência e frequentemente exercem papéis de liderança na comunidade.

A política de modernização da agricultura da década de 1970/1980, com aposta na maquinaria pesada, uso de agroquímicos e a substituição da mão de obra dos trabalhadores, acabou por expulsar milhares de pessoas para Curitiba e região metropolitana em busca de trabalho nas indústrias recém-criadas. Ao final dos anos de 1980, com o processo de redemocratização e de abertura democrática, a expressão de pobreza e miserabilidade foi denunciada pelos 
movimentos sociais que estavam em processo de reorganização. São dessa época as primeiras ocupações de terras como forma de denunciar o latifúndio e a violência no campo.

Entre as denúncias feitas pelos movimentos e organizações sociais do campo está a precariedade e o fechamento das escolas no campo. As ocupações e a retomada dos territórios levavam famílias inteiras novamente para o campo exigindo uma série de estruturas nas áreas da saúde, educação, infraestrutura e acesso em diferentes regiões do estado, onde boa parte dos municípios não dispunha de estrutura para atender a esse contingente de pessoas que da noite para o dia chegava a esses espaços (HAMMEL, 2013; JANATA, 2012).

Em nível nacional, a partir do I Encontro dos Educadores da Reforma (I ENERA), que ocorreu em 1997, as denúncias da precarização e da negação de escolas no meio rural ganhou dimensões nacionais e internacionais. A Conferência Mundial sobre Educação para Todos, em Jomtien na Tailândia, de 5 a 9 de março de 1990, mobilizou vários países - entre eles o Brasil - e as organizações que se mobilizavam para elevar os índices de escolarização. Isso teve certo impacto na I Conferência Nacional de Educação do Campo, em 1998, tendo entre os participantes organismos internacionais, como o Fundo das Nações Unidas para Infância (Unicef) e a Organização das Nações Unidas para a Educação, a Ciência e a Cultura (Unesco), e também foram entidades participantes a Conferência Nacional dos Bispos do Brasil (CNBB) o Movimento dos Trabalhadores Rurais Sem Terra (MST) e a Universidade de Brasília (UnB). A síntese feita pelos promotores denunciou a não existência de políticas em educação e a precária situação da educação rural no Brasil, mas anunciava as transgressões que fazem vivas inúmeras experiências de escolas e de propostas pedagógicas que ultrapassam as políticas ou a não política destinada aos trabalhadores e aos povos do campo (KOLLING; NERY; MOLINA, 1999). 
A conferência teve uma repercussão nacional e, a partir dela, vários estados passam a organizar as conferências estaduais. $\mathrm{O}$ Paraná, a Comissão Pastoral da Terra (CPT) e o MST assumiram a frente de organizar a conferência (PEREIRA, 2013) No ano de 2000 ocorreu na pequena cidade de Porto Barreiro, PR, a II Conferência Estadual por uma Educação do Campo, com a participação de 600 educadores/as, sendo 200 organizações representadas, entre elas, movimentos dos trabalhadores do campo, associações, sindicatos, escolas e universidades (PEREIRA, 2013, p. 41).

Algumas definições importantes foram sistematizadas e passaram a ser pauta de luta dessas entidades no estado, além de também ser criada a Articulação Paranaense Por Uma Educação do Campo, que desde então vem tendo espaço de atuação e reunião dos diferentes sujeitos que lutam pela Educação do Campo no Paraná. Os anos 2000 foram decisivos para constituição da Educação do Campo no estado, com a criação da Coordenação de Educação do Campo na Secretaria de Estado da Educação do Paraná (SEED). Essa coordenação foi um importante espaço de negociações das pautas estaduais e da criação de uma legislação que normatizava as ações e os princípios políticos e pedagógicos para as Escolas do Campo no Estado. Entre os documentos, destacamos as diretrizes curriculares de 2006/2008, a Resolução n. 4.783/2010 que reconhece a Educação do Campo como política pública do Estado do Paraná e o Parecer CEE/ CEB n. 1.011/10, que instituiu normas e princípios para a implementação da Educação Básica do Campo no Sistema Estadual de Ensino do Paraná. Soma-se a isso um vasto processo de formação inicial e continuada dos educadores, desencadeado por várias universidades, movimentos e organizações sociais e pela própria SEED.

Entre 2003 e 2010 foram vários encontros, seminários, conferências e grupos de estudos sobre as especificidades e singularidades das escolas e da Educação do Campo. Desse processo, além das 
diretrizes, destacamos os Projetos Políticos Pedagógicos das Escolas Itinerantes do Paraná ${ }^{4}$ e das Escolas das Ilhas e em territórios Quilombolas, também do Estado do Paraná. No âmbito da formação inicial, destacam-se a criação dos cursos de Licenciatura em Educação do Campo nas universidades estaduais e federais no estado. Em 2009, foram criados os cursos na Universidade Estadual do Centro-Oeste (UNIOESTE), da Universidade Federal Tecnológica (UTFPR) de Dois Vizinhos, PR, da Universidade Estadual do Oeste do Paraná (UNIOESTE), na Universidade Federal da Fronteira Sul (UFFS) e na Universidade Federal do Paraná (UFPR) - setor litoral. Cabe ainda destacar os Cursos de especialização lato sensu desenvolvidos pela UFPR em 2007 e pela Unicentro a partir de 2010. Vale ressaltar que essas experiências formativas foram constituindo uma concepção e uma forma escolar que perpassa a organização curricular dos processos educativos, parte deles sistematizados nas diretrizes. A organização por área do conhecimento e a perspectiva da interdisciplinaridade, associadas à conexão com a realidade e com a identidade de cada comunidade, foram os elementos estruturais da proposta.

Nesse sentido, a especificidade e a singularidade da Educação do Campo e da Escola do Campo no Paraná estão intrinsecamente articuladas ao seu papel dentro das comunidades camponesas. Por isso, concordamos com Martins (2012, p. 121), quando ele diz que:

As comunidades do campo apresentam singularidades. A principal é que a escola, além de uma instituição educativa, é também um "símbolo cultural", uma instituição de convergência na vida comunitária, que, ao contrário dos conglomerados urbanos,

\footnotetext{
${ }^{4}$ As escolas itinerantes são localizadas em áreas de ocupação/acampamentos do MST no Estado do Paraná, os educandos são matriculados em uma escola estadual, chamada escola Base (HAMMEL, 2013). Até 2017, essa escola era o colégio estadual do Campo Iraci Salete Strozak, localizado no assentamento Marcos Freire, em Rio Bonito do Iguaçu, PR.
} 
mantém elementos de coletividade, estreitos laços de solidariedade e participação, que podem solidificar o processo de gestão democrática da escola.

Assim, escola é mais do que o prédio escolar, são as relações construídas, a vida que pulsa com todas as suas contradições e possibilidades de emancipação. Convergir para a vida comunitária exige a disponibilidade de tempo para entender a fundo o significado e as consequências que o estudo, a ciência e a cultura colocam no cotidiano das famílias. Uma escola conectada com esses elementos avança na medida em que passa a ser mais um espaço de organização, luta e formação dos trabalhadores e povos do campo.

O singular nesses espaços é também o que materializa a sua especificidade, pois, como já evidenciamos até aqui, o processo organizativo e de luta dos movimentos e das organizações sociais do campo pautam a política para essas escolas. Nesse sentido, não é possível compreender a Educação do Campo sem sua natureza de luta e recorte de classe, no caso os trabalhadores e os povos do campo com toda sua especificidade e particularidade, sejam eles Sem Terras, quilombolas, pequenos agricultores, ribeirinhos, ilhéus, agricultores familiares, indígenas, faxinalenses, entre outros espalhados nos 399 municípios paranaenses. Martins (2012, p. 126) considera necessário, ao abordar a especificidade das escolas do campo, tê-las

[...] como sujeito social e político vinculado a demandas populares [...] a especificidade da educação do campo e do movimento que a circunda, exige pensar para além do que foi frisado sobre a função da escola e o desenvolvimento local, é também compreender a ação escolar em si, como colaboradora desse desenvolvimento, concomitante à formação do sujeito educando.

A partir das eleições de 2011, há uma nova configuração da política de educação estadual, e as especificidades da Educação do 
Campo passaram a ser elementos secundários. A preocupação com os índices, sem considerar as estruturas dessas escolas e comunidades, acaba por exigir uma reconfiguração do próprio movimento da Articulação Paranaense Por uma Educação do Campo. O fechamento de escolas no campo, os processos forçados de multisseriação e a negação da legitimidade dos cursos de licenciatura em Educação do Campo passam a exigir uma concentração maior em assegurar espaços conquistados na concepção e nos princípios construídos até então.

Nesse contexto é que emerge e se torna pressão política a aprovação da Base Nacional Comum Curricular (BNCC). Nos espaços de debate da Educação do Campo, nas universidades, nos grupos de estudos e pesquisas, nos fóruns e, sobretudo, na Articulação Paranaense, além da luta por garantir a especificidade, a particularidade e a singularidade das organizações da Escola do Campo, por isso, têm sido denunciado veementemente o caráter "privatista" da BNCC. Algumas análises ainda não aprofundadas levantam também uma retomada dos antigos Parâmetros Nacionais Curriculares (PCNs), derrotados na década de 1990, apresentando a BNCC como uma novidade antiga. $\mathrm{O}$ fato é que há um profundo descontentamento com a BNCC e, também, com todas as políticas estabelecidas para a educação nesse último período (2013- 2019), mas também há uma firme consciência e disposição para a luta dos sujeitos coletivos. No âmbito da política de formação inicial e da própria reformulação das licenciaturas, a partir de 2015, foram anunciadas mudanças que vão se consolidando nas universidades e que buscam adequar os currículos às novas exigências. O Programa Residência Pedagógica está no bojo dessas mudanças.

A Universidade Federal da Fronteira Sul aderiu ao Programa e, desde então, no coletivo dos cursos de Licenciatura em Educação do Campo, tem se discutindo como garantir a especificidade, a singularidade e a particularidade da Educação do Campo frente às 
mudanças empreendidas com a BNCC, e também com as demais políticas do Ministério da Educação (MEC) para a Educação Básica. Cada núcleo tem realizado estudos sistemáticos sobre a BNCC, mas também sobre o currículo, as diretrizes e outros documentos que aglutinam elementos sobre o que está em jogo diante da nova política nacional. Outra ação fundamental priorizada no plano de ação na escola é a pesquisa da realidade, feita por meio do inventário da realidade, que será detalhado no próximo item deste trabalho. O inventário tem sido fundamental não apenas para caracterizar as escolas, mas para identificar questões fundamentais para o trabalho pedagógico nesses espaços. Na sequência, vamos adentrar em alguns elementos suscitados na experiência desses seis meses de residência pedagógica do núcleo de Educação do Campo.

\section{A Diversidade de Escolas Atendidas e o Processo de Pesquisa e de Docência por meio do Inventário da Realidade}

O inventário da realidade é uma metodologia fundamental dentro dos princípios pedagógicos e filosóficos da Educação do Campo e se apresenta como "ferramenta para levantamento e registro organizado de aspectos materiais ou imateriais de uma determinada realidade", de acordo com o guia metodológico para uso das escolas do campo discutido e compartilhado a partir do Seminário Educação em Agroecologia nas Escolas do Campo, Veranópolis, RS (IEJC), 16 a 18 de junho 2016. A partir da observação e da descrição da realidade, as escolas do campo podem fundamentar suas práticas pedagógicas qualificando a produção de conhecimento. Embora o sistema educacional, por si só, tente constantemente homogeneizar as escolas, o currículo e as práticas de ensino-aprendizagem, sabemos que a 
escola não pode ser pensada de maneira descolada da realidade com qual se confunde. Nesse sentido, negar a importância de conhecer a realidade escolar é negar a própria natureza da escola, configurando um amplo processo de alienação do trabalho pedagógico.

O inventário da realidade das escolas fez parte do subprojeto dos núcleos do PRP no campus da UFFS em Laranjeiras do Sul e contribuiu de maneira importante na qualificação da atuação dos/ as estudantes residentes. Cada uma das escolas participantes do Programa construiu um inventário por meio da atuação dos/as estudantes residentes em suas observações, registros fotográficos e pesquisas documentais. Ao final do processo - que obviamente não produz um inventário definitivo da realidade escolar - os dados foram socializados em um seminário reunindo residentes, professores/as preceptores/as, coordenadoras/es de núcleo e comunidade acadêmica e regional. Os/as residentes apontaram diferentes aspectos da produção do inventário e refletiram sobre os dados coletados com o propósito de fazer o planejamento seguinte do subprojeto, qual seja, o de sintetizar essas reflexões em artigos científicos.

O inventário da realidade escolar demonstrou, como já apontado, que os desafios vivenciados por estudantes de licenciatura que realizam sua formação a partir do regime de alternância são compartilhados com os/as estudantes das escolas do campo onde realizam a residência. Os desafios do transporte, da participação da comunidade na escola/universidade, da infraestrutura (bibliotecas, espaços de vivência), da evasão escolar, da gravidez compulsória ou precoce e da conciliação da vida escolar/acadêmica com o trabalho e a organização familiar são apenas alguns exemplos de como a produção do inventário da realidade representou uma reflexão mais ampla sobre a iniciação à docência de jovens estudantes de licenciatura que são também sujeitos do campo, transpassados por suas especificidades e contradições. 
Se partirmos do pressuposto de que a realidade é um instrumento fundamental para a formação dos sujeitos, ela precisa ser apreendida por todos para que possa fundamentar o processo pedagógico vinculado às questões da atualidade. Neste sentido, há necessidade de inventariar a realidade e buscar nela os elementos que contribuirão para a construção do conhecimento. (HAMMEL; FARIAS; SAPELLI, 2015, p. 74)

Da perspectiva da antropologia e das ciências sociais, essa "realidade" a que se está disposto a inventariar precisa ser problematizada no próprio olhar do observador. Isto é, na pesquisa etnográfica, a chamada "descrição densa" (GEERTZ, 2013), não se propõe - nem poderia fazê-lo - a realizar uma descrição "fiel da realidade". Trata-se de, a partir da relação entre os sujeitos da pesquisa/inventário e os sujeitos pesquisados, estabelecer um diálogo entre categorias de pensamento, modos de ver e sentir. É a própria relação entre os sujeitos que se apresenta como objeto de análise, para além de uma "representação da realidade". Isso significa que a realidade material e imaterial dos sujeitos é compreendida pela própria materialidade dos significados produzidos nas relações sociais estabelecidas entre eles. Com isso, enfatizamos que a reflexão oriunda da produção dos inventários pelos/as residentes - estudantes de licenciatura em regime de alternância - refletiu a relação e a identificação complexa desses sujeitos com os sujeitos das escolas do campo, escolas estas que alguns residentes até já frequentaram.

A seguir, apresentamos um quadro das escolas participantes do PRP a partir de alguns dados trazidos pelos inventários realizados: 
Quadro 1 - Lista das escolas

\begin{tabular}{|c|c|c|c|}
\hline Escolas & Municípios & $\begin{array}{l}\text { Número de } \\
\text { Estudantes }\end{array}$ & Perfil da Comunidade e da Escola \\
\hline $\begin{array}{c}\text { Colégio } \\
\text { Estadual } \\
\text { do Campo } \\
\text { Iraci Salete } \\
\text { Strozak }\end{array}$ & $\begin{array}{l}\text { Rio Bonito do } \\
\text { Iguaçu }\end{array}$ & 458 & $\begin{array}{l}\text { Escola do Campo localizada em } \\
\text { assentamento da reforma agrá- } \\
\text { ria. Seu projeto educativo dialoga } \\
\text { com os princípios da Educação do } \\
\text { Campo e da Pedagogia do MST. } \\
\text { Sua primeira estrutura foi cons- } \\
\text { truída pela comunidade e sua in- } \\
\text { tencionalidade pedagógica traz } \\
\text { um forte vínculo com a realidade. } \\
\text { Além das aulas, oferece uma série } \\
\text { de outros processos formativos } \\
\text { para os educandos, materializados } \\
\text { na auto-organização dos coleti- } \\
\text { vos. Oferta Ensino Fundamental } \\
\text { II, Ensino Médio, Formação de } \\
\text { Docentes e Educação de Jovens e } \\
\text { Adultos (EJA). }\end{array}$ \\
\hline $\begin{array}{c}\text { Escola } \\
\text { Itinerante } \\
\text { Herdeiros } \\
\text { do Saber }\end{array}$ & $\begin{array}{l}\text { Rio Bonito } \\
\text { Iguaçu }\end{array}$ & 500 & $\begin{array}{l}\text { Escola do Campo, localizada no } \\
\text { acampamento Herdeiros da Ter- } \\
\text { ra do Primeiro de Maio em Rio } \\
\text { Bonito do Iguaçu. A escola está } \\
\text { vinculada ao Colégio Estadual do } \\
\text { Campo Iraci Salete Strozak, que } \\
\text { responde legalmente pela docu- } \\
\text { mentação escolar, contratação de } \\
\text { funcionários, repasse de recursos } \\
\text { e prestação de relatórios, certi- } \\
\text { ficações e contas junto à SEED. } \\
\text { A escola itinerante traz com espe- } \\
\text { cificidade a forte conexão com o } \\
\text { processo de luta vivido pelas famí- } \\
\text { lias acampadas, participando nas } \\
\text { lutas, enfrentamentos e, também, } \\
\text { nas conquistas empreendidas. } \\
\text { A comunidade garante todas as } \\
\text { estruturas físicas necessárias para } \\
\text { a existência e participação dos es- } \\
\text { paços pedagógicos. São ofertadas } \\
\text { todas as etapas da Educação Básica } \\
\text { e, também, a EJA. }\end{array}$ \\
\hline
\end{tabular}




\begin{tabular}{|c|c|c|c|}
\hline Escolas & Municípios & $\begin{array}{l}\text { Número de } \\
\text { Estudantes }\end{array}$ & Perfil da Comunidade e da Escola \\
\hline $\begin{array}{c}\text { Colégio } \\
\text { Estadual } \\
\text { Indígena } \\
\text { Kokoj Ty } \\
\text { Han }\end{array}$ & Mangueirinha & 350 & $\begin{array}{l}\text { Escola indígena que atende à co- } \\
\text { munidade Sede na Terra Indígena } \\
\text { de Mangueirinha, traz a especifici- } \\
\text { dade da comunidade e busca uma } \\
\text { conexão com a cultura nas festas } \\
\text { e eventos promovidos pela escola. } \\
\text { Além disso os educandos têm au- } \\
\text { las de língua materna, com profes- } \\
\text { sora da comunidade. Há uma forte } \\
\text { presença das lideranças na escola, } \\
\text { inclusive na seleção dos professo- } \\
\text { res que precisam ter a anuência } \\
\text { delas lecionar. }\end{array}$ \\
\hline $\begin{array}{c}\text { Colégio } \\
\text { Estadual } \\
\text { do Campo } \\
\text { Tereza } \\
\text { Cristina }\end{array}$ & $\begin{array}{l}\text { Cândido de } \\
\text { Abreu }\end{array}$ & 250 & $\begin{array}{l}\text { Escola do Campo, localizada em } \\
\text { comunidade de pequenos agri- } \\
\text { cultores às margens do Rio Ivaí. } \\
\text { A Educação do Campo é conhe- } \\
\text { cida e incentivada sobretudo pela } \\
\text { direção da escola, que busca in- } \\
\text { centivar processos de diálogos } \\
\text { com a comunidade e realidade } \\
\text { local. Tem sofrido com o processo } \\
\text { de esvaziamento do campo, prin- } \\
\text { cipalmente com a saída dos jovens } \\
\text { que não veem perspectiva de con- } \\
\text { tinuar na comunidade. }\end{array}$ \\
\hline
\end{tabular}

Fonte: Inventários da Realidade

\section{Considerações Finais}

A partir da experiência adquirida com os inventários nas escolas do campo e a observação das especificidades e dos desafios da realização do Programa em cursos de alternância, entendemos que, ao qualificar a iniciação à docência dos estudantes, o Programa também reflete sobre si mesmo a partir das contradições que a política educacional atual impõe, fundamentalmente à Educação do Campo. 
A alternância é a base de uma educação verdadeiramente atrelada à especificidade dos contextos camponeses. Mas, como conciliar a temporalidade da Educação do Campo e a temporalidade da BNCC das novas diretrizes curriculares e do novo Ensino Médio? Desafios que aceitamos ao mergulhar no universo de reflexões que o Programa Residência Pedagógica insere em nossas práticas como docentes e coordenadoras de núcleo. Reflexões que os/as estudantes residentes têm desenvolvido em seu movimento constante em solo um tanto irregular. Reflexões iniciais, mas com potencial expressivo no movimento mais amplo de compreender a escola e a educação hoje.

\section{Referências}

CALDART, Roseli S. et al. (org.) Dicionário da Educação do Campo. Rio de Janeiro, São Paulo: Escola Politécnica de Saúde Joaquim Venâncio; Expressão Popular, 2012.

GEERTZ, Clifford. A interpretação das culturas. Rio de Janeiro: LTC, 2013.

HAMMEL, Ana C. Ciclos de Formação Humana no Colégio Estadual do Campo Iraci Salete Strozak. 2013. 162f. Dissertação (Mestrado) - Universidade Estadual do Oeste do Paraná, Cascavel, 2013.

HAMMEL, Ana C. FARIAS, Maria Isabel; SAPELLI, Marlene L. S. Complexos de Estudo: do inventário ao Plano de Estudos. In: SAPELLI, Marlene L. S.; FREITAS, Luiz Carlos; CALDART, Roseli S. Caminhos para a transformação da escola 3. $1^{\text {a }}$ Ed. São Paulo: Expressão Popular, 2015. 
JANATA, Natacha E. Juventude que ousa lutar: trabalho, educação e militância dos jovens assentados do MST. 2012. 278f. Tese (Doutorado) - Universidade Federal de Santa Catarina, Florianópolis, 2012.

KOLLING, Edgar J.; NERY, I.; MOLINA, Mônica C. Por uma educação básica do campo: Memória. Brasília: UnB, 1999.

MARTINS, Fernando J. Gestão democrática e Educação do Campo. RBPAE - v. 28, [S.l.], n. 1, p. 112-128, jan./abr. 2012.

PEREIRA, Amarildo N. Territorialidades da Educação do Campo no sudoeste do Paraná na última década (2000-2010). 2013. 121 f. Dissertação (Mestrado) - Universidade Estadual do Oeste do Paraná, Francisco Beltrão, 2013. 